\title{
Applications of Local Climate Zone Classification Scheme to Improve Urban Sustainability: A Bibliometric Review
}

\author{
Jiao Xue ${ }^{1}$, Ruoyu You ${ }^{2}$, Wei Liu ${ }^{3}$ (I) , Chun Chen ${ }^{4}$ and Dayi Lai ${ }^{1, *}$ \\ 1 School of Design, Shanghai Jiao Tong University, Shanghai 200240, China; xuejiao@sjtu.edu.cn \\ 2 Department of Building Services Engineering, The Hong Kong Polytechnic University, Kowloon, \\ Hong Kong 999077, China; ruoyu.you@polyu.edu.hk \\ 3 Division of Sustainable Buildings, Department of Civil and Architectural Engineering, \\ KTH Royal Institute of Technology, Brinellvägen 23, 10044 Stockholm, Sweden; wei.liu@byv.kth.se \\ 4 Department of Mechanical and Automation Engineering, The Chinese University of Hong Kong, \\ Shatin, N.T., Hong Kong 999077, China; chunchen@mae.cuhk.edu.hk \\ * Correspondence: dayi_lai@sjtu.edu.cn; Tel.: +86-18721019661
}

Received: 10 September 2020; Accepted: 27 September 2020; Published: 30 September 2020

\begin{abstract}
Many of the sustainable urban development issues, such as human heath, energy consumption, carbon emission, are related to the climate of cities. As a result, research insights gained in urban climate study can be applied to improve urban sustainability. Although the Local Climate Zones (LCZ) scheme was originally proposed to provide a standardized classification of landscapes to study urban air temperature, its use was not limited to the study of urban heat islands. This study explores the applications of LCZ scheme in various research domains by conducting a bibliometric analysis in CiteSpace on over 800 articles that cites the original article of LCZ. These articles cover a wide range of research categories including meteorology, atmospheric science, environmental science, remote sensing, building technology, civil engineering, ecology, urban studies, etc. The LCZ scheme facilitates urban climate data collection by refining monitoring network, providing reasonable modelling input, and improving database documentation. In addition to the study of urban heat islands, the LCZ scheme was applied in studies of urban thermal comfort, human health, building energy consumption, and carbon emission. The diffusion of the LCZ scheme to other research domains offers an example that the development of urban climate research advances sustainable urban development. This review provides insights of multidisciplinary studies related to urban climate for policy-makers, urban specialists, architects, ecologists, and others.
\end{abstract}

Keywords: Local Climate Zone (LCZ); urban climate; urban heat island; thermal comfort; carbon emission; sustainable urban development; building energy consumption

\section{Introduction}

A total of $56 \%$ of the world population lives in cities in 2020 [1], as a result of rapid urbanization. Urbanization greatly changes the form, fabric, structure, and metabolism of a landscape, and thus alters the local climate of that area. Urban heat island (UHI), which refers to the higher ambient temperature in a city compared to its rural parts [2], has deteriorated urban sustainability. For example, higher ambient temperature worsens human thermal comfort in the summer [3], and may even led to increased mortality [4] due to increased heat stress. In addition, UHI advances the start of season for urban plants [5], and contributes to greater air conditioning energy consumption [6] for buildings.

Due to the significant impact of UHI on urban sustainability, researchers have made large effort in understanding UHI. However, the documentation of UHI intensity in literature may be inconsistent 
and inaccurate due to vague definition of urban and rural areas. What is described as urban in one city or region differs from that of another. In order to provide an objective protocol for measuring the strength of urban heat island, and to facilitate controlled inter and intra comparisons of UHI results, Stewart and Oke [7] proposed the Local Climate Zones (LCZ) classification system. The LCZ scheme clusters landscapes into different "local climate zones" based on their approximate ability to modify local surface climates due to their typical fabric, land cover, structure, and metabolism.

The scheme has attracted huge research attention. Eight years after the proposal of the LCZ scheme in 2012, the original article has been cited more than 800 times (as of July 2020, Web of Science database). While the original purpose of the LCZ scheme is to simplify and standardize urban temperature observations, its application has been diffused to many other research areas that are related to sustainable urban development, such as urban planning [8], building energy consumption [9-13], human perception of outdoor spaces [14], etc.

The diffusion of the LCZ classification system to related domains has demonstrated the rich connotation and multidisciplinary nature of urban climate research. To provide useful information and to identify research opportunities and new frontiers to the urban climate and related research communities, this study reviews the applications of the LCZ scheme in different research topics with aid from a bibliometric tool. The contents summarized in this paper are by no means exhaustive, but an indication of the trend of using LCZ in urban research.

\section{Methods}

\subsection{Concept, Data, and Tool}

Stewart and Oke [7] formally proposed the LCZ Scheme in their article "Local Climate Zones for urban temperature studies" in Bulletin of American Meteorological Society in 2012. According to Stewart and Oke [7], urban or rural spaces were classified into one of the 17 local climate zones based on the fabric (thermal admittance, surface albedo), land cover (plan fraction occupied by buildings, vegetation, and impervious ground), structure (sky view factor, aspect ratio, roughness element height), and metabolism (anthropogenic heat output) of that space. 10 out of the 17 zones are for "built types" with various spatial arrangements and heights, and the remaining 7 types are natural landscapes without artificial structures. Spaces clustered into the same LCZ have similar ability to modify local surface climate. From the definition, it can be seen that LCZ was originally created for the purposes of urban climate studies.

The original LCZ manuscript [7] has been cited by a large number of references covered by various disciplines. Our analysis has used all the articles and reviews in English that cite Stewart and Oke [7] in the Web of Science Core Collection dataset for the bibliometric analysis. The retrieval of data was performed on 26 July 2020, and 884 bibliographic items with their titles, keywords, abstracts, cited references, research categories, and authors and their institutions were exported for further analysis in the CiteSpace 5.7.R1 [15], which is a program for quantifying and visualizing relationships among scientific literatures. CiteSpace provides a visual gateway to the literature of scholarly publications. It shows on the collective behavior of peer scholars and experts in terms of which articles they cite, how often they cited, and contexts in which they cite.

\subsection{Performed Analyses}

The downloaded dataset was firstly descriptively analyzed by studying its temporal distribution, contributing countries, institutions, journals, and authors. Then, as the main objective of this study, various research topics that used LCZ were identified by CiteSpace by generating and clustering the co-citation network. Selected publications from these research domains were further reviewed. Finally, CiteSpace was used to reveal the network of different disciplines that adopted the LCZ scheme. 


\section{Results}

\subsection{Descriptive Analysis}

The first part of the Results section shows the basic statistics of the LCZ-related publications. Figure 1 shows the temporal distribution of the number of publications that cite the original article [7] from 2013 to 2020 July. The researches related to LCZ dramatically increased from 19 in 2013 to 220 in 2019, highlighting the growing of global interest on the LCZ scheme.

Table 1 lists the main contributing journals. These journals cover a wide range of subjects, such as meteorology, environmental science, building science, urban science, energy, and remote sensing technology. Urban Climate published the most items (97), which is not surprising, since LCZ is originally derived from urban climate research. Science of the Total Environment, Building and Environment, Sustainable Cities and Society, and Remote Sensing ranked from 2 to 4 with 48, 39, 35, and 33 contributing records, respectively.

Table 1. A ranking of contributing journals.

\begin{tabular}{|c|c|c|}
\hline$\#$ & Journal & \# of Records \\
\hline 1 & Urban Climate & 97 \\
\hline 2 & Science of The Total Environment & 48 \\
\hline 3 & Building and Environment & 39 \\
\hline 4 & Sustainable Cities and Society & 35 \\
\hline 5 & Remote Sensing & 33 \\
\hline 6 & International Journal of Climatology & 27 \\
\hline 7 & Landscape and Urban Planning & 25 \\
\hline 8 & Sustainability & 22 \\
\hline 9 & Theoretical and Applied Climatology & 22 \\
\hline 10 & Journal of Applied Meteorology and Climatology & 17 \\
\hline 11 & Atmosphere & 16 \\
\hline 12 & Energy and Buildings & 14 \\
\hline 13 & Remote Sensing of Environment & 13 \\
\hline 14 & Climate & 12 \\
\hline 15 & Environmental Research Letters & 12 \\
\hline 16 & $\begin{array}{l}\text { IEEE Journal of Selected Topics in Applied Earth } \\
\text { Observations and Remote Sensing }\end{array}$ & 12 \\
\hline 17 & Urban Forestry and Urban Greening & 12 \\
\hline 18 & Atmospheric Environment & 11 \\
\hline 19 & Journal of Geophysical Research Atmospheres & 11 \\
\hline 20 & ISPRS International Journal of Geo Information & 10 \\
\hline 21 & International Journal of Biometeorology & 9 \\
\hline
\end{tabular}




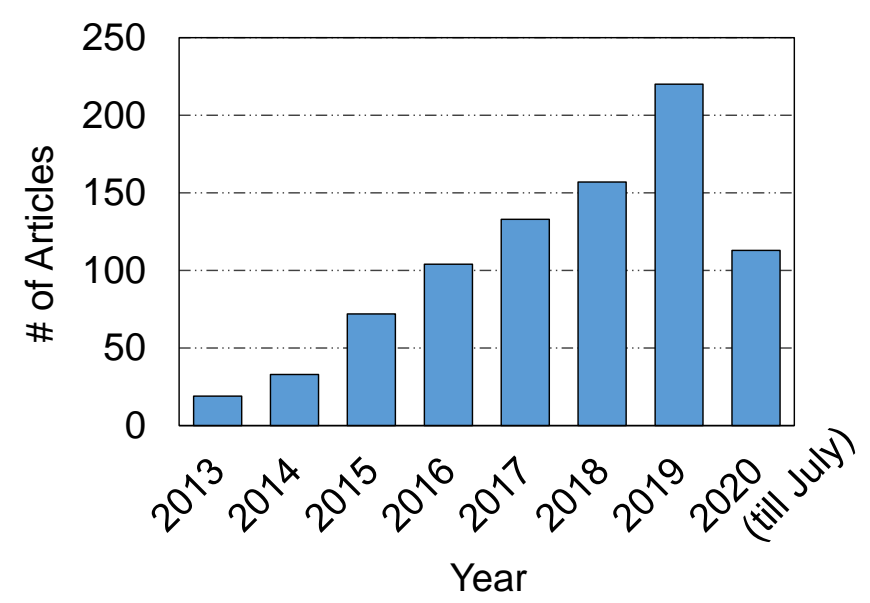

Figure 1. Annual distribution of the bibliographic dataset.

Table 2 shows the major contributing countries in terms of publication. Four countries have more than 100 LCZ-related publications, with China taking the first place with 276 records, followed by the USA with 199 records. Germany and England have contributed 145 and 103 items, respectively.

Table 2. A list of contributing countries and contributed number of records.

\begin{tabular}{|c|c|c|}
\hline$\#$ & Countries & \# of Records \\
\hline 1 & China & 276 \\
\hline 2 & USA & 199 \\
\hline 3 & Germany & 145 \\
\hline 4 & England & 103 \\
\hline 5 & Canada & 62 \\
\hline 6 & Australia & 57 \\
\hline 7 & Italy & 47 \\
\hline 8 & Netherlands & 42 \\
\hline 9 & Austria & 36 \\
\hline 10 & Belgium & 36 \\
\hline 11 & France & 36 \\
\hline 12 & Japan & 32 \\
\hline 13 & Singapore & 30 \\
\hline 14 & India & 26 \\
\hline 15 & South Korea & 26 \\
\hline 16 & Spain & 24 \\
\hline 17 & Switzerland & 23 \\
\hline 18 & Ireland & 21 \\
\hline 19 & Brazil & 19 \\
\hline 20 & Czech Republic & 19 \\
\hline 21 & Sweden & 17 \\
\hline 22 & Hungary & 16 \\
\hline 23 & Greece & 15 \\
\hline
\end{tabular}


The top contributing institutions are presented in Table 3. Arizona State University ranked first (112 records), followed by Chinese Academy of Sciences (87 records). Among the top 19 institutions, China and Germany have four institutions, while America has three.

Table 3. A ranking of contributing institutions by number of records.

\begin{tabular}{|c|c|c|}
\hline$\#$ & Institutions & \# of Records \\
\hline 1 & Arizona State University & 112 \\
\hline 2 & Chinese Academy of Sciences & 87 \\
\hline 3 & University of Reading & 52 \\
\hline 4 & University of Hamburg & 50 \\
\hline 5 & University of Hong Kong & 37 \\
\hline 6 & Helmholtz Association & 33 \\
\hline 7 & University of New South Wales Sydney & 28 \\
\hline 8 & Chinese University of Hong Kong & 25 \\
\hline 9 & German Aerospace Centre & 22 \\
\hline 10 & Ghent University & 22 \\
\hline 11 & University of California System & 22 \\
\hline 12 & Centre National De La Recherche Scientifique & 21 \\
\hline 13 & Wageningen University Research & 21 \\
\hline 14 & KU Leuven & 19 \\
\hline 15 & National University of Singapore & 19 \\
\hline 16 & China Meteorological Administration & 18 \\
\hline 17 & Humboldt University of Berlin & 17 \\
\hline 18 & University College Dublin & 17 \\
\hline 19 & Massachusetts Institute of Technology & 16 \\
\hline
\end{tabular}

Table 4 shows the top 10 most productive authors across all countries. Bechtel B ranked first with 35 items, followed by Grimmond CSB, who published 33 records.

Table 4. Top 10 authors ranked by number of contributions.

\begin{tabular}{ccc}
\hline$\#$ & Authors & \# of Records \\
\hline 1 & Bechtel B & 35 \\
\hline 2 & Grimmond CSB & 33 \\
\hline 3 & Ren C & 24 \\
\hline 4 & Demuzere M & 21 \\
\hline 5 & Mills G & 16 \\
\hline 6 & Masson V & 15 \\
\hline 7 & Xu Y & 15 \\
\hline 8 & Martilli A & 14 \\
\hline 9 & Middel A & 14 \\
\hline 10 & See L & 14 \\
\hline
\end{tabular}




\subsection{Research Topics}

In order to identify the research topics for publications related to LCZ, a document co-citation network was generated. Co-citation is defined as the frequency with which two documents are cited together by other documents. A co-citation network provides a tool for monitoring scientific development [16]. After generating the co-citation network, the publications with close relationships were grouped into 12 clusters, as shown in Figure 2. Label was created automatically for each cluster in CiteSpace by summarizing the main theme of publications in a cluster. Ranked by the size (number of publications) of the clusters, the main labels are surface urban heat island (SUHI), outdoor thermal comfort, local climate zones, Surface Urban Energy and Water Balance Scheme (SUEWS), crowdsourcing, human health, risk assessment, carbon dioxide, building performance simulation, knowledge base, heat wave, and urban databases. These labels demonstrate the wide range of topics covered in the LCZ-related researches.
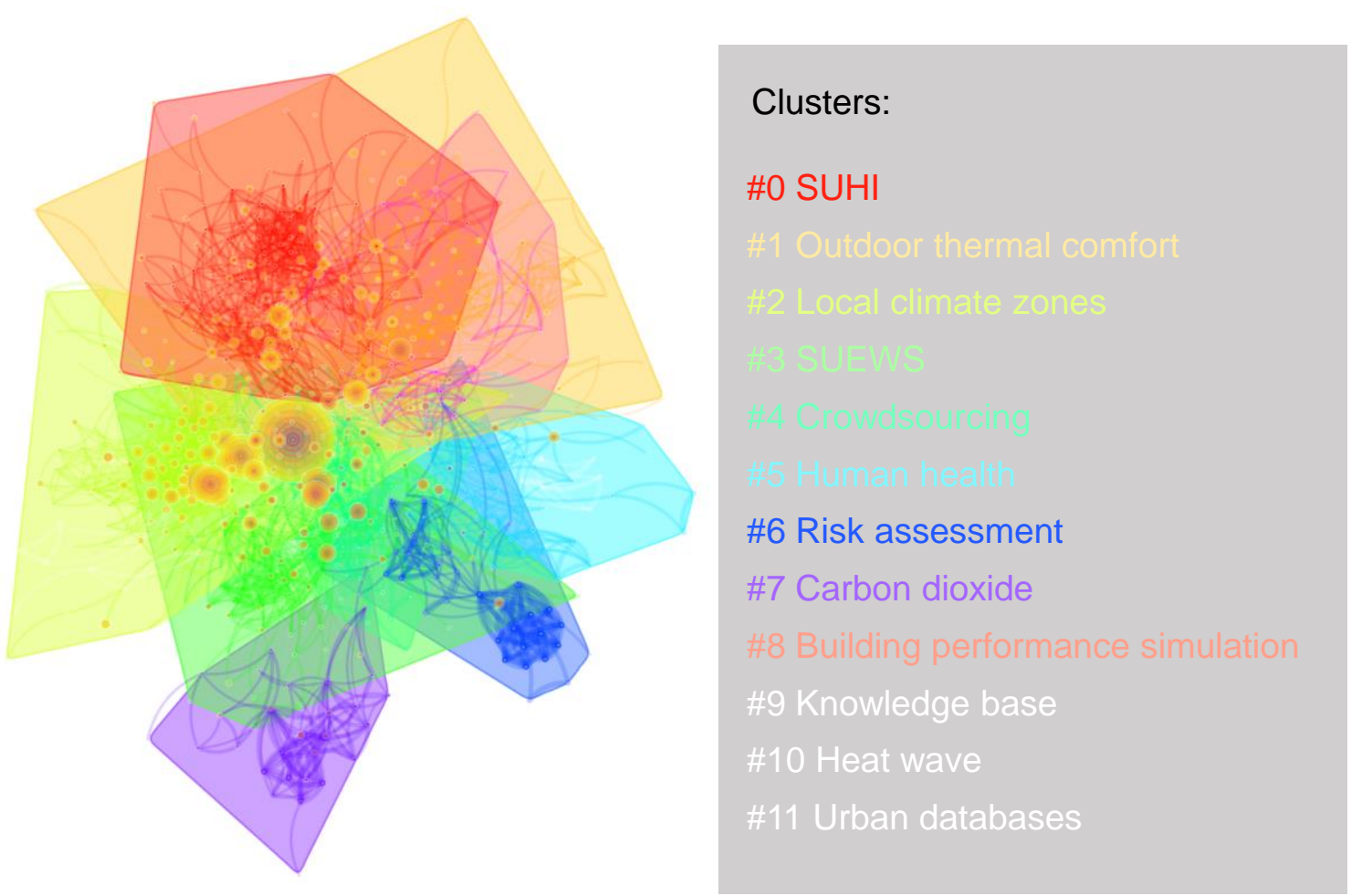

Figure 2. The co-citation network and cluster.

Table 5 further provides the detailed size information and the top five labels identified in CiteSpace for each cluster. The research topics were summarized from the identified terms. For example, the largest cluster (\#0) had a lot of terms indicating techniques, indicators, and tools associated with urban heat island, while the terms in second largest cluster (\#1) were about index, research approach, and modelling tool of outdoor thermal comfort. Thus, urban heat island and outdoor thermal comfort were chosen as research topics identified from cluster \#0 and cluster \#1, respectively. By using a similar approach, cluster \#2 was named as local climate zone, cluster \#3 as model, \#4 as monitoring, \#5, \#6, and \#10 as human health, \#7 as carbon emission, \#8 as building energy, \#9 and \#11 as database. 
Table 5. Cluster description and the top five labels within each cluster.

\begin{tabular}{|c|c|c|}
\hline Cluster ID & Size & Top 5 Labels \\
\hline 0 & 109 & $\begin{array}{c}\text { surface urban heat island, land surface temperature, MODIS } \\
\text { (Moderate Resolution Imaging Spectroradiometer), thermal remote } \\
\text { sensing, urban heat island effect }\end{array}$ \\
\hline 1 & 102 & $\begin{array}{l}\text { outdoor thermal comfort, Envi-met, thermal comfort, PET } \\
\text { (Physiologically Equivalent Temperature), field survey }\end{array}$ \\
\hline 2 & 101 & $\begin{array}{c}\text { local climate zones, remote sensing, Sentinel-2, urban areas, } \\
\text { convolutional neural network }\end{array}$ \\
\hline 3 & 78 & $\begin{array}{c}\text { SUEWS (Surface Urban Energy and Water Balance Scheme), energy } \\
\text { balance, WRF (Weather Research and Forecasting Model), land } \\
\text { surface model, regional climate modeling }\end{array}$ \\
\hline 4 & 61 & $\begin{array}{l}\text { crowdsourcing, citizen weather station, cyber-infrastructure, wireless } \\
\text { sensor networks, crowdsourcing air temperature }\end{array}$ \\
\hline 5 & 45 & $\begin{array}{l}\text { human health, NDVI (normalized difference vegetation index), } \\
\text { thermal behavior, synoptic weather type, cool pavements }\end{array}$ \\
\hline 6 & 40 & $\begin{array}{c}\text { risk analysis, mortality, Germany, intra-urban air temperature, } \\
\text { Envi-met modeling }\end{array}$ \\
\hline 7 & 29 & $\begin{array}{c}\text { carbon dioxide, eddy covariance, source area, urban environment, } \\
\text { emissions inventory }\end{array}$ \\
\hline 8 & 29 & $\begin{array}{l}\text { building performance simulation, sea breeze, density, urban weather } \\
\text { generator, urban building energy performance }\end{array}$ \\
\hline 9 & 6 & $\begin{array}{c}\text { knowledge base, personal weather station, relative land surface } \\
\text { temperature, human health, building }\end{array}$ \\
\hline 10 & 5 & $\begin{array}{c}\text { heat wave, thermal comfort, air temperature, local climate zones, } \\
\text { urban climate }\end{array}$ \\
\hline 11 & 5 & $\begin{array}{c}\text { urban databases, } \mathrm{CO}_{2} \text { fluxes, urban climate maps, urban canopy } \\
\text { layer model, MApUCE }\end{array}$ \\
\hline
\end{tabular}

As shown in Figure 3, the nine topics were further organized into three levels, with the first level being the researches of the LCZ scheme itself. The second level includes topics of database, monitoring, and modeling, which are related to LCZ data and adopting LCZ in monitoring and modeling to obtain urban climate data. Level 3 uses the climate data to address specific urban issues such as UHI, thermal comfort, health, building energy, and carbon emission. The following provides a topic by topic review of the research areas related to LCZ. The review is not trying to be inclusive, but to provide examples of researches areas around LCZ and application of such a concept from urban climate research to related subjects.

\subsubsection{Level 1: Local Climate Zones (LCZ)}

A large portion of publications is relate to the study of the LCZ scheme itself, such as the evaluation, application, and improvement of the scheme. Stewart et al. [17] have justified the division of urban and rural landscapes into LCZs by demonstrating significant temperature difference among LCZs from site observations and atmosphere-surface model simulations. The authors suggested further evaluation of LCZ by advanced numerical models and more UHI observations.

Generating LCZ maps for cities is an important step to facilitate urban studies, and some studies were mainly about the generations of LCZ classification maps for various cities, such as in Hong Kong [18], Xi'an [19], and three metropolitan areas of Texas, U.S. [20]. According to Zheng et al. [18], there are mainly three methods of LCZ classification methods: manual sampling, remote sensing, and geographical information system (GIS). The remote sensing method has been adopted by the World Urban Database and Access Portal Tools (WUDAPT). However, Ren et al. [21] has found the WUDAPT 
method to be inaccurate for creating LCZ maps for Chinese cities due to the lack of building height data, and a feasible refinement method was proposed by the authors.

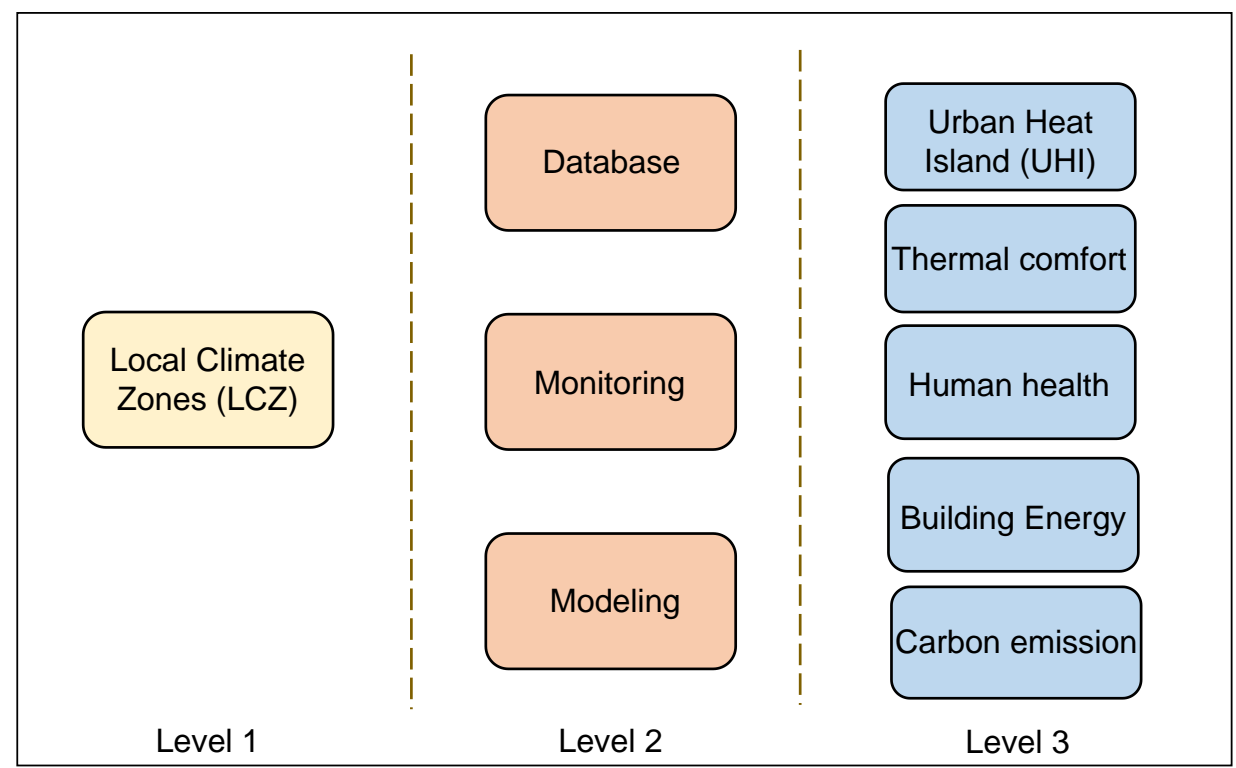

Figure 3. Identified research topics related to Local Climate Zones (LCZ).

\subsubsection{Level 2: Database}

Consistent, detailed, and easily available urban data is essential to promote the development of urban climate and related sciences. The WUDAPT project was launched to provide useful information that describes aspects of the form and function of cities at a detailed spatial resolution [22]. The WUDAPT initiative is a global, bottom up, self-organized effort to fill the data gaps needed to solve the global challenges of sustainable cities and communities, and as a guide to facilitate climate-based actions [23]. The urban information in WUDAPT is conveyed through the form of LCZs at different levels of details, and the remote sensing data is used to create LCZs for urban and natural landscapes of cities in WUDAPT [24].

\subsubsection{Level 2: Monitoring}

Urban meteorological monitoring is important because it is an essential mean to obtain climatic data for further assessment urban heat island, outdoor thermal comfort, health, building energy consumption, etc. With environmental sensors becoming more compact, inexpensive, and reliable, it is possible to deploy a dense urban meteorological monitoring network for a better understanding of the heterogeneous urban environments [25]. Crowdsourcing, the utilization of residents or public sensors for the obtain of data, is an alternative of urban monitoring. By using smartphone battery temperature, UHI effect has been found in some of the LCZs in São Paulo, Brazil [26]. The LCZ scheme is also useful to ensure that certain representative areas are monitored when designing the urban monitoring network [27].

\subsubsection{Level 2: Modeling}

As stated in the original article [7], one of the applications of LCZ is to provide urban canopy parameters for numerical climate models to predict temperature, wind, precipitation, etc. Alexander et al. [28] examined the validity of using LCZ data to run the Surface Urban Energy and Water Balance model (SUEWS). They found the simulation using the LCZ scheme and meteorological data from a station outside the urban area showed good agreement with the observation records across multiple seasons, thus validating the capability of LCZs for the parameterization of SUEWS. 


\subsubsection{Level 3: Urban Heat Islands (UHI)}

Since the original purpose of LCZ scheme is to provide a standardized classification of site in urban heat islands (UHI) studies, it is not surprising that UHI is the largest cluster in Table 5. UHI includes surface temperature UHI and air temperature UHI [29]. Surface UHI is the temperature difference of urban and rural grounds and can be measured by remote sensing observations. During the UHI study, researchers classified the investigated sites into specific LCZs and reported the measured or predicted air temperature, surface temperature, and related parameters. For example, Middel et al. [30] simulated the mid-afternoon microclimate of five LCZs in Phoenix, Arizona, USA, and concluded compact scenarios were favorable for daytime cooling. Van Hove et al. [31] used data from a monitoring network in Rotterdam agglomeration that covered a range of LCZs for the analysis of temporal and spatial variability of UHI. UHI influences human thermal comfort, health, building energy consumption, and carbon emission. As a result, the LCZ scheme can be further applied in the above topics.

\subsubsection{Level 3: Outdoor Thermal Comfort}

Human thermal comfort in outdoor spaces is significantly related to the microclimate condition, such as air temperature, radiation, wind, etc. [32-34]. These parameters in urban spaces are spatially variable due to the modification of surface energy and radiation balance in different local climate zones. As a result, occupants have different thermal comfort perceptions in various LCZ zones, as evidenced by Lau et al. [35] in Hong Kong, China, Liu et al. [36] in Shenzhen, China, and Das et al. [37] in Eastern India. The LCZ scheme helps thermal comfort researchers to document the studied sites in a standardized way [38,39]. The scheme also offers a tool for researchers to select suitable sites to conduct thermal comfort survey [14].

\subsubsection{Level 3: Human Health}

Urban climate is a driver of many health issues, such as heat-stress related mortality, vector-borne disease, and air quality problems. There is a well-established connection between extreme heat and summer excess mortality [4]. Since LCZs contain important urban morphological characteristics that is related to spatial air temperature regimes, Verdonck et al. [40] examined the potential of using LCZ maps as heat stress assessment tool in three cities in Belgium: Antwerp, Brussels, and Ghent. The effect of thermal stress on human health can also be assessed by using indices such as Physiologically Equivalent Temperature (PET) [41] or the Universal Thermal Climate Index (UTCI) [42]. In addition to heat stress, air quality and its impact on human health in urban spaces is a pressing issue in city. The distributions of air pollution concentration are controlled by the urban flow field, which is strongly impacted by urban geometry [43]. Vector-borne disease is another health problem related to urban climate, since there is a link between air temperature and the vector behaviors. In Sub-Saharan Africa, to study intra-urban malaria risk, Brousse et al. [44] combined LCZs and very high resolution satellite imagery for the parameterization of a simple urban canopy model, and derived a Temperature Suitability Index (TSI) map for the evaluation of vector-borne malaria disease.

\subsubsection{Level 3: Building Energy}

Since the building and its heating, ventilation, and air-conditioning (HVAC) system directly exchange heat with the environment adjacent to the building, the cooling and heating energy of that building is externally determined by its surrounding microclimate. Building energy simulation provides useful insights for the design, construction, operation, and control of buildings, but traditional simulation usually uses the meteorological data collected from rural or suburban stations as background climate input, and thus fails to account for the altered climatic condition by urban elements. Yang et al. [9] simulated and compared the energy performance of buildings located in different local climate zones (LCZ) and found a difference of up to around $20 \%$ in cooling and heating loads. The result indicates 
the importance of using site-specific data for a more accurate evaluation of energy performance of buildings in urban contexts.

\subsubsection{Level 3: Carbon Emission}

Concentrated anthropogenic activities in urban areas has led to intense carbon emission. Since the morphological and functional structure of city spaces is closely associated with the carbon emissions, it may be practical to adopt the LCZ scheme to study building carbon emission in cities. Wu et al. [45] preliminarily investigated the building carbon emission of different LCZs in Shanghai, and demonstrated that LCZ 1 (compact high rise) emitted more carbon than other LCZs. LCZs also provide a method to categorize the feature of investigated sites in carbon modeling research. For example, Jarvi et al. [46] validated their $\mathrm{CO}_{2}$ exchange model against the data collected from two sites, which were classified as LCZ 2 and LCZ 6.

\subsection{Research Subjects}

In order to visualize the relationships among subjects that adopts the LCZ scheme, CiteSpace was used the generate the network of co-occurring research categories. The network was shown in Figure 4. The thickness of the links between subjects denotes the strength of relationships, and the size of the node represents usage frequency of the subjects. We found that environmental science \& ecology, meteorology and atmospheric sciences, remote sensing, construction and building technology, engineering are major subjects with large nodes. Minor subjects include urban studies, green and sustainable science and technology, ecology, geography, public administration, forestry, etc.

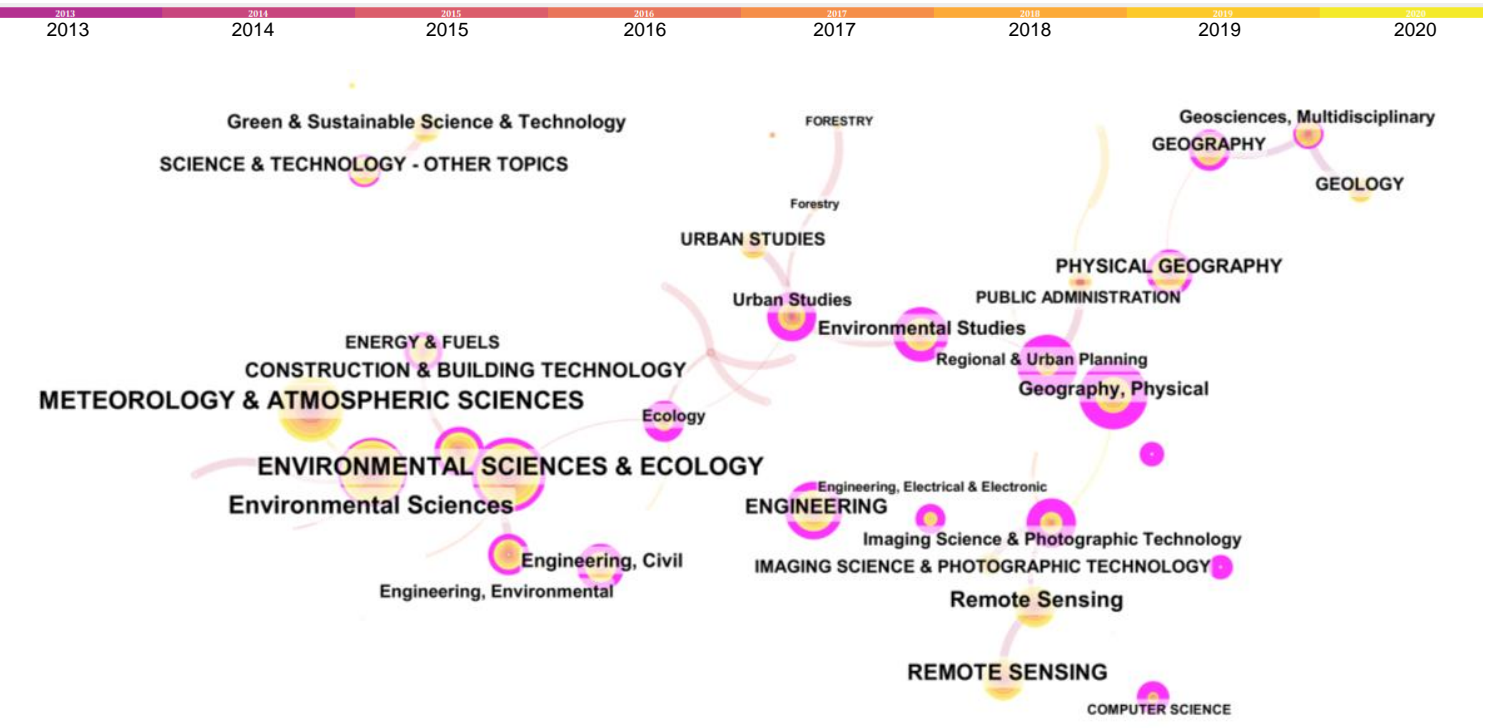

Figure 4. Network of co-occurring research categories.

The rings around a node shows the temporal evolution of the subject. The inner rings show the older usage while the outer rings are indications of newer usage. It can be seen that the studies related to environmental sciences, meteorology and atmospheric science, and remote sensing are older than the studies in urban planning, engineering and geography, etc. This phenomenon indicates that LCZ was originally developed and used in the meteorological, environmental sciences and remote sensing areas, but later, its uses were diffused to the fields of urban studies, engineering, construction and building technology. Table 6 lists the top 10 research categories and their percentage. 
Table 6. Top 10 research categories and their percentages.

\begin{tabular}{ccc}
\hline$\#$ & Category & $\%$ \\
\hline 1 & Environmental sciences \& ecology & 32 \\
\hline 2 & Meteorology \& atmospheric sciences & 15 \\
\hline 3 & Remote sensing & 6 \\
\hline 4 & Engineering & 6 \\
\hline 5 & Construction \& building technology & 5 \\
\hline 6 & Science \& technology - other topics & 4 \\
\hline 7 & Geography, physical & 3 \\
\hline 8 & Engineering, civil & 3 \\
\hline 9 & Green \& sustainable science \& technology & 3 \\
\hline 10 & Energy \& fuels & 3 \\
\hline
\end{tabular}

\section{Discussion}

From the above review, it can be found that the LCZ scheme advanced the urban studies in two ways. Firstly, some urban studies such as thermal comfort, health, and building energy highly depend on the urban climate data. Urban climate data collection was improved with LCZs by aiding the monitoring, modeling, and database creation. Second, the LCZ scheme provided a guideline for related studies to select suitable spaces to conduct investigations, and the scheme also offers a standardized way to document studied areas.

The LCZ scheme was also applied in topics beyond the research areas detected in our bibliometric analysis. For example, urban ventilation is strongly impacted by architectural patterns and may be studied with the help of LCZs. Zhao et al. [47] offered evidences that the LCZ classification scheme could effectively indicate local-scale urban ventilation performance. Yang et al. [48] adopted LCZs in the study of urban ventilation in Shanghai, while Zhou et al. [49] found that LCZs could be employed to understand the cooling potential of sea-land breeze in Sendai, Japan. Actually, LCZs can be applied in any research fields influenced by the urban heat island; to name a few, urban plant and urban air pollution studies. For example, the start of season (SOS) for plants was found to be associated with $\mathrm{UHI}$ [5], and LCZs can be useful to detail the spatial variation of plant SOS. Lower urban aerosol pollution island (UAPI) is detected with increased UHI [50,51], and LCZs can also be used to provide more details.

With the expansion of applications in urban climate research, it is necessary to always be careful when applying LCZs to other domains. Bartesaghi et al. [52] pointed out that LCZs are not well-suited for the microclimatic analysis of green infrastructure (GI), since the LCZ scheme provides limited information on the dynamic interactions between vegetated and built environments. As a response, Bartesaghi et al. [53] developed green infrastructure typology (GIT) framework.

\section{Conclusions}

The Local Climate Zone (LCZ) scheme was originally proposed to provide a standard method for consistent documentation of urban and natural landscapes for urban heat island studies. However, the LCZ scheme has been used in many subjects related to urban sustainability. It is interesting to know the diffusion of knowledge in urban climate research to other disciplines. This study investigated the diffusion of the LCZ application to other research domains by applying a bibliometric method. The analysis of a bibliometric dataset has identified nine research topics, includes LCZ itself, creating urban database, urban climate monitoring, urban climate modeling, urban heat island, outdoor thermal comfort, health, building energy consumption, and carbon emission. The LCZ scheme has advanced the related research topics such as human thermal comfort, health, building energy consumption by 
providing more reliable and detailed urban climate data and a consistent classification method to document the studied spaces. An analysis of research categories shows that the LCZ scheme and classification method was initially developed and frequently used in subjects like meteorological science, environmental science, and remote sensing. Later, its uses were diffused to applied fields such as urban and regional planning, building and construction technology, engineering, and ecology, etc.

Author Contributions: Writing-original draft presentation: J.X.; Writing-review and editing: D.L. and C.C.; Conceptualization: R.Y. and D.L.; Methodology: J.X. and W.L.; Software: J.X.; All authors have read and agreed to the published version of the manuscript.

Funding: The research was funded by the "Chenguang Program" supported by the Shanghai Education Development Foundation and Shanghai Municipal Education Commission through Grant No. 18CG12. This work also received external funding from Shanghai Sailing Program of Science and Technology Commission of Shanghai Municipality through Grant No. 19YF1424800.

Conflicts of Interest: The authors declare no conflict of interest.

\section{References}

1. Population Reference Bureau. 2020 World Population Data Sheet; Population Reference Bureau: Washington, DC, USA, 2020.

2. Lai, D.; Liu, W.; Gan, T.; Liu, K.; Chen, Q. A review of mitigating strategies to improve the thermal environment and thermal comfort in urban outdoor spaces. Sci. Total Environ. 2019, 661, 337-353. [CrossRef] [PubMed]

3. Lai, D.; Lian, Z.; Liu, W.; Guo, C.; Liu, W.; Liu, K.; Chen, Q. A comprehensive review of thermal comfort studies in urban open spaces. Sci. Total Environ. 2020, 742, 140092. [CrossRef] [PubMed]

4. Vanos, J.K.; Kalkstein, L.S.; Sanford, T.J. Detecting synoptic warming trends across the US Midwest and implications to human health and heat-related mortality. Int. J. Climatol. 2015, 35, 85-96. [CrossRef]

5. Meng, L.; Mao, J.; Zhou, Y.; Richardson, A.D.; Lee, X.; Thornton, P.E.; Ricciuto, D.M.; Li, X.; Dai, Y.; Shi, X.; et al. Urban warming advances spring phenology but reduces the response of phenology to temperature in the conterminous United States. Proc. Natl. Acad. Sci. USA 2020, 117, 4228-4233. [CrossRef]

6. Li, X.; Zhou, Y.; Yu, S.; Jia, G.; Li, H.; Li, W. Urban heat island impacts on building energy consumption: A review of approaches and findings. Energy 2019, 174, 407-419. [CrossRef]

7. Stewart, I.D.; Oke, T.R. Local Climate Zones for Urban Temperature Studies. Bull. Am. Meteorol. Soc. 2012, 93, 1879-1900. [CrossRef]

8. Perera, N.G.R.; Emmanuel, R. A “Local Climate Zone” based approach to urban planning in Colombo, Sri Lanka. Urban Clim. 2018, 23, 188-203. [CrossRef]

9. Yang, X.; Peng, L.L.H.; Jiang, Z.; Chen, Y.; Yao, L.; He, Y.; Xu, T. Impact of urban heat island on energy demand in buildings: Local climate zones in Nanjing. Appl. Energy 2020, 260. [CrossRef]

10. Lee, D.Y.; Seo, B.M.; Yoon, Y.B.; Hong, S.H.; Choi, J.M.; Lee, K.H. Heating energy performance and part load ratio characteristics of boiler staging in an office building. Front. Energy 2018, 13, 339-353. [CrossRef]

11. Sahdev, R.K.; Kumar, M.; Dhingra, A.K. A comprehensive review of greenhouse shapes and its applications. Front. Energy 2017, 13, 427-438. [CrossRef]

12. Talele, S.; Traylor, C.; Arpan, L.; Curley, C.; Chen, C.-F.; Day, J.; Feiock, R.; Hadzikadic, M.; Tolone, W.J.; Ingman, S.; et al. Energy modeling and data structure framework for Sustainable Human-Building Ecosystems (SHBE)-A review. Front. Energy 2018, 12, 314-332. [CrossRef]

13. Zhang, H.; Zhang, C.; Wen, F.; Xu, Y. A comprehensive energy solution for households employing a micro combined cooling, heating and power generation system. Front. Energy 2018, 12, 582-590. [CrossRef]

14. Sharmin, T.; Steemers, K.; Matzarakis, A. Analysis of microclimatic diversity and outdoor thermal comfort perceptions in the tropical megacity Dhaka, Bangladesh. Build. Environ. 2015, 94, 734-750. [CrossRef]

15. Chen, C. CiteSpace II: Detecting and visualizing emerging trends and transient patterns in scientific literature. J. Am. Soc. Inf. Sci. Technol. 2006, 57, 359-377. [CrossRef]

16. Small, H. Co-citation in the scientific literature: A new measure of the relationship between two documents. J. Am. Soc. Inf. Sci. 1973, 24, 265-269. [CrossRef]

17. Stewart, I.D.; Oke, T.R.; Krayenhoff, E.S. Evaluation of the 'local climate zone' scheme using temperature observations and model simulations. Int. J. Climatol. 2014, 34, 1062-1080. [CrossRef] 
18. Zheng, Y.; Ren, C.; Xu, Y.; Wang, R.; Ho, J.; Lau, K.; Ng, E. GIS-based mapping of Local Climate Zone in the high-density city of Hong Kong. Urban Clim. 2018, 24, 419-448. [CrossRef]

19. He, S.; Zhang, Y.; Gu, Z.; Su, J. Local climate zone classification with different source data in Xi'an, China. Indoor Built Environ. 2018, 28, 1190-1199. [CrossRef]

20. Zhao, C.; Jensen, J.; Weng, Q.; Currit, N.; Weaver, R. Application of airborne remote sensing data on mapping local climate zones: Cases of three metropolitan areas of Texas, U.S. Comput. Environ. Urban Syst. 2019, 74, 175-193. [CrossRef]

21. Ren, C.; Cai, M.; Li, X.; Zhang, L.; Wang, R.; Xu, Y.; Ng, E. Assessment of Local Climate Zone Classification Maps of Cities in China and Feasible Refinements. Sci. Rep. 2019, 9, 18848. [CrossRef]

22. Ching, J.; Mills, G.; Bechtel, B.; See, L.; Feddema, J.; Wang, X.; Ren, C.; Brousse, O.; Martilli, A.; Neophytou, M.; et al. WUDAPT: An Urban Weather, Climate, and Environmental Modeling Infrastructure for the Anthropocene. Bull. Am. Meteorol. Soc. 2018, 99, 1907-1924. [CrossRef]

23. Mills, G.; Ching, J.; See, L.; Bechtel, B.; Foley, M. An introduction to the WUDAPT project. In Proceedings of the 9th International Conference on Urban Climate, Toulouse, France, 20-24 July 2015; pp. 20-24.

24. Bechtel, B.; Alexander, P.; Böhner, J.; Ching, J.; Conrad, O.; Feddema, J.; Mills, G.; See, L.; Stewart, I. Mapping Local Climate Zones for a Worldwide Database of the Form and Function of Cities. ISPRS Int. J. Geo-Inf. 2015, 4, 199-219. [CrossRef]

25. Muller, C.L.; Chapman, L.; Grimmond, C.S.B.; Young, D.T.; Cai, X. Sensors and the city: A review of urban meteorological networks. Int. J. Climatol. 2013, 33, 1585-1600. [CrossRef]

26. Uijlenhoet, R.; Van Delden, A.J.; Steeneveld, G.J.; Leijnse, H.; Overeem, A.; Pape, J.J.; Droste, A.M. Crowdsourcing Urban Air Temperatures through Smartphone Battery Temperatures in São Paulo, Brazil. J. Atmos. Ocean. Technol. 2017, 34, 1853-1866. [CrossRef]

27. Chapman, L.; Muller, C.L.; Young, D.T.; Warren, E.L.; Grimmond, C.S.B.; Cai, X.-M.; Ferranti, E.J.S. The Birmingham Urban Climate Laboratory: An Open Meteorological Test Bed and Challenges of the Smart City. Bull. Am. Meteorol. Soc. 2015, 96, 1545-1560. [CrossRef]

28. Alexander, P.J.; Mills, G.; Fealy, R. Using LCZ data to run an urban energy balance model. Urban Clim. 2015, 13, 14-37. [CrossRef]

29. Oke, T.R.; Mills, G.; Christen, A.; Voogt, J.A. Urban Climates; Cambridge University Press: Cambridge, UK, 2017.

30. Middel, A.; Häb, K.; Brazel, A.J.; Martin, C.A.; Guhathakurta, S. Impact of urban form and design on mid-afternoon microclimate in Phoenix Local Climate Zones. Landsc. Urban Plan. 2014, 122, 16-28. [CrossRef]

31. van Hove, L.W.A.; Jacobs, C.M.J.; Heusinkveld, B.G.; Elbers, J.A.; van Driel, B.L.; Holtslag, A.A.M. Temporal and spatial variability of urban heat island and thermal comfort within the Rotterdam agglomeration. Build. Environ. 2015, 83, 91-103. [CrossRef]

32. Xia, L.; Lan, L.; Tang, J.; Wan, Y.; Lin, Y.; Wang, Z. Bed heating improves the sleep quality and health of the elderly who adapted to no heating in a cold environment. Energy Build. 2020, 210, 109687. [CrossRef]

33. He, M.; Lian, Z.; Chen, P. Evaluation on the performance of quilts based on young people's sleep quality and thermal comfort in winter. Energy Build. 2019, 183, 174-183. [CrossRef]

34. Shen, J.; Zhang, X.; Lian, Z. Impact of wooden versus nonwooden interior designs on office workers' cognitive performance. Percept. Mot. Skills 2020, 127, 36-51. [CrossRef]

35. Lau, K.K.-L.; Chung, S.C.; Ren, C. Outdoor thermal comfort in different urban settings of sub-tropical high-density cities: An approach of adopting local climate zone (LCZ) classification. Build. Environ. 2019, 154, 227-238. [CrossRef]

36. Liu, L.; Lin, Y.; Xiao, Y.; Xue, P.; Shi, L.; Chen, X.; Liu, J. Quantitative effects of urban spatial characteristics on outdoor thermal comfort based on the LCZ scheme. Build. Environ. 2018, 143, 443-460. [CrossRef]

37. Das, M.; Das, A.; Mandal, S. Outdoor thermal comfort in different settings of a tropical planning region: A study on Sriniketan-Santiniketan Planning Area (SSPA), Eastern India. Sustain. Cities Soc. 2020, 63. [CrossRef]

38. Salata, F.; Golasi, I.; de Lieto Vollaro, R.; de Lieto Vollaro, A. Outdoor thermal comfort in the Mediterranean area. A transversal study in Rome, Italy. Build. Environ. 2016, 96, 46-61. [CrossRef]

39. Shooshtarian, S.; Ridley, I. The effect of individual and social environments on the users thermal perceptions of educational urban precincts. Sustain. Cities Soc. 2016, 26, 119-133. [CrossRef] 
40. Verdonck, M.-L.; Demuzere, M.; Hooyberghs, H.; Beck, C.; Cyrys, J.; Schneider, A.; Dewulf, R.; Van Coillie, F. The potential of local climate zones maps as a heat stress assessment tool, supported by simulated air temperature data. Landsc. Urban Plan. 2018, 178, 183-197. [CrossRef]

41. Höppe, P. The physiological equivalent temperature-A universal index for the biometeorological assessment of the thermal environment. Int. J. Biometeorol. 1999, 43, 71-75. [CrossRef] [PubMed]

42. Jendritzky, G.; de Dear, R.; Havenith, G. UTCI-Why another thermal index? Int. J. Biometeorol. 2012, 56, 421-428. [CrossRef] [PubMed]

43. Ching, J.K.S. A perspective on urban canopy layer modeling for weather, climate and air quality applications. Urban Clim. 2013, 3, 13-39. [CrossRef]

44. Brousse, O.; Georganos, S.; Demuzere, M.; Vanhuysse, S.; Wouters, H.; Wolff, E.; Linard, C.; van Lipzig, N.P.M.; Dujardin, S. Using Local Climate Zones in Sub-Saharan Africa to tackle urban health issues. Urban Clim. 2019, 27, 227-242. [CrossRef]

45. Wu, Y.; Sharifi, A.; Yang, P.; Borjigin, H.; Murakami, D.; Yamagata, Y. Mapping building carbon emissions within local climate zones in Shanghai. Energy Procedia 2018, 152, 815-822. [CrossRef]

46. Järvi, L.; Havu, M.; Ward, H.C.; Bellucco, V.; McFadden, J.P.; Toivonen, T.; Heikinheimo, V.; Kolari, P.; Riikonen, A.; Grimmond, C.S.B. Spatial Modeling of Local-Scale Biogenic and Anthropogenic Carbon Dioxide Emissions in Helsinki. J. Geophys. Res. Atmos. 2019, 124, 8363-8384. [CrossRef]

47. Zhao, Z.; Shen, L.; Li, L.; Wang, H.; He, B.-J. Local Climate Zone Classification Scheme Can Also Indicate Local-Scale Urban Ventilation Performance: An Evidence-Based Study. Atmosphere 2020, 11, 776. [CrossRef]

48. Yang, J.; Jin, S.; Xiao, X.; Jin, C.; Xia, J.; Li, X.; Wang, S. Local climate zone ventilation and urban land surface temperatures: Towards a performance-based and wind-sensitive planning proposal in megacities. Sustain. Cities Soc. 2019, 47. [CrossRef]

49. Zhou, X.; Okaze, T.; Ren, C.; Cai, M.; Ishida, Y.; Watanabe, H.; Mochida, A. Evaluation of urban heat islands using local climate zones and the influence of sea-land breeze. Sustain. Cities Soc. 2020, 55. [CrossRef]

50. Li, H.; Sodoudi, S.; Liu, J.; Tao, W. Temporal variation of urban aerosol pollution island and its relationship with urban heat island. Atmos. Res. 2020, 241. [CrossRef]

51. Li, H.; Meier, F.; Lee, X.; Chakraborty, T.; Liu, J.; Schaap, M.; Sodoudi, S. Interaction between urban heat island and urban pollution island during summer in Berlin. Sci. Total Environ. 2018, 636, 818-828. [CrossRef]

52. Bartesaghi-Koc, C.; Osmond, P.; Peters, A. Spatio-temporal patterns in green infrastructure as driver of land surface temperature variability: The case of Sydney. Int. J. Appl. Earth Obs. Geoinf. 2019, 83. [CrossRef]

53. Bartesaghi Koc, C.; Osmond, P.; Peters, A. A Green Infrastructure Typology Matrix to Support Urban Microclimate Studies. Procedia Eng. 2016, 169, 183-190. [CrossRef] 